\title{
Nopiloa y la representación de la tierra fecunda
}

A Figurilla Registrada COMO PJ282 (fig. I) en el Catálogo general del Museo de Antropología de Xalapa forma parte de una ofrenda de siete "esculturas sonajero" rescatadas del entierro secundario número 6 en el vertedero de Nopiloa, asentamiento ubicado en la subárea centro-sur de Ve-

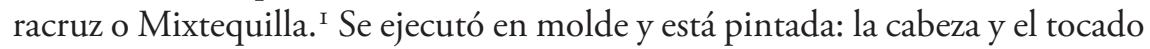
combinan un color crema u ocre con blanco y rojo; los ojos y las comisuras de la boca muestran restos de color blanco; en el huipil ${ }^{2}$ predomina el color rojo flanqueado por áreas de tono crema, a la vez que el enredo muestra trazos de color sepia. Destaca por estar articulada de los brazos. La modificación intencional de su cráneo ha sido calificada de "tabular erecta" y se ha notado que sus dientes fueron "limados". Pertenece al tipo de estatuillas del Clásico tardío llamadas "mayoides". Esta designación se debe a su gran semejanza de forma, iconografía y materia "de pasta fina y delgada" con las figurillas del estilo Jaina (Campeche) y Jonuta (bajo Usumacinta) del Clásico tardío. Sus orejeras circulares se moldearon con la efigie del dios de la lluvia, tempestad, rayo y guerra (fig. 2a), o Tlaloc, como lo refiere el arqueólogo Alfonso Medellín Zenil mediante la denominación náhuatl del Posclásico tardío. ${ }^{3}$

I. Alfonso Medellín Zenil, Cerámicas del Totonacapan: exploraciones arqueológicas en el centro de Veracruz, Xalapa, Universidad Veracruzana, I960, p. 98, lám. 56; Nopiloa: exploraciones arqueológicas, Xalapa, Universidad Veracruzana, 1987, p. 66, fig. 42; Hasso von Winning, "Figurines with Movable Limbs from Ancient Mexico", Ethnos, núm. 23 (I), I958, pp. I-60, fig. 38.

2. El huipil, de lengua náhuatl, es un tipo de blusa o vestido.

3. Sin embargo, Javier Urcid no descarta que se trate de nubes (comunicación personal, 2008). 


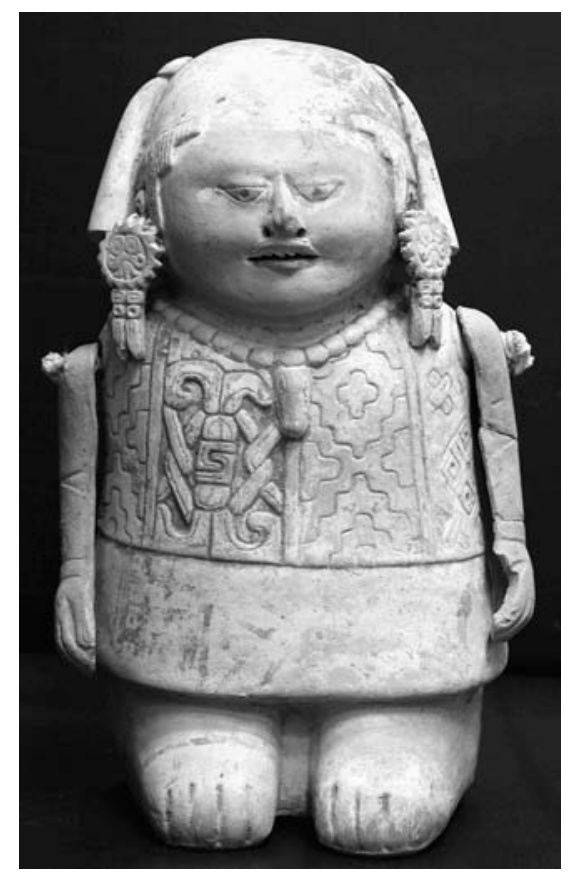

I. Figurilla PJ282 procedente de Nopiloa, Museo de Antropología de Xalapa. Foto: Sergio Vásquez Zárate, 2008. Reproducción autorizada por el Instituto Nacional de Antropología e Historia. Conaculta-INAH-Méx.

La cabeza del ser sobrenatural está contorneada por volutas, a semejanza de ciertas descripciones teotihuacanas donde éste aparece entre espacios acuáti$\cos$ (fig. 2b). Volutas extendidas vertical u horizontalmente son recurrentes en la imaginería mesoamericana del agua, donde figuran la superficie acuática en la iconografía del Posclásico. Al mismo tiempo, el diseño circular de las orejeras indica que éstas son chalchihuites, piedra verde cuyo modelo es el jade, que significa el agua y lo precioso en general. Originalmente, pudieron haberse pintado de azul verdoso. El conjunto lleva un pendiente; en la sección superior está compuesto de dos cuentas que tienden a una forma cuadrangular y que, junto con otras discoidales y esféricas, se refieren al chalchihuitl. En la sección inferior se distingue por dos cuentas circulares perforadas de las que cuelgan dos elementos en forma de pluma. Este segmento de las orejeras parece describir el glifo de sangre zapoteco catalogado como "glifo Epsilon", y figura una gota de sangre. ${ }^{4}$

4. El glifo Epsilon se presenta a menudo a modo de un elemento vertical y perforado, "indicación [de] que estaba suspendido verticalmente, como un pendiente o una orejera” (comunicación 


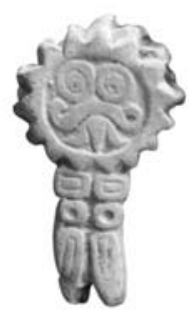

a)

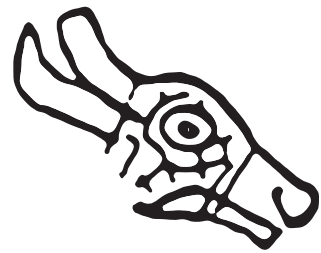

d)

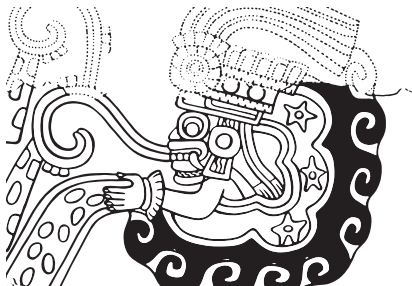

b)

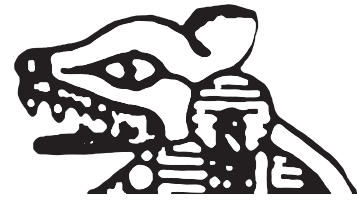

c)

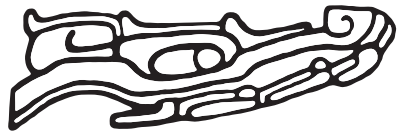

f)

2a) Detalle de PJ282, orejera que lleva la efigie del dios de la lluvia; b) dios de la lluvia en ambiente acuático contorneado por volutas de agua, Teotihuacan, Palacio de Zacuala. Dibujo tomado de Arthur Miller, The Mural Painting of Teotihuacan, Washington, D.C., Dumbarton Oaks, I973, fig. 20; c) tlacuache. Dibujo tomado de Eduard Seler, Las imágenes de animales en los manuscritos mexicanos y mayas, México, Casa Juan Pablos, 2004, fig. I 85 ; d) armadillo. Dibujo tomado de Seler, op. cit., fig. 233; e) cánido, PJ4687, procedente de Apachital, Museo Veracruzano de Xalapa. Foto: Patricia Janet Barragán. Reproducción autorizada por el Instituto Nacional de Antropología e Historia. Conaculta-INAH-Méx.; f) cocodrilo en monumento en piedra procedente de Antigua. Dibujo tomado de Javier Urcid, Stone Monuments from Nopiloa, Veracruz, Massachusetts, Brandeis University, 2005, fig.7.

El peinado de PJ 282 consiste en mechones de corte escalonado sobre las sienes que flanquean una cabeza rapada, con los restos de pintura blanca, roja y ocre. La mirada presenta estrabismo bilateral convergente. El pendiente de perlas esféricas lleva una cuenta tubular zoomorfa que representa a un animal cuyos ojos aparecen colocados simétricamente en la parte superior y cuyo hocico es alargado. Podría tratarse de un mamífero: tlacuache (fig. $2 \mathrm{c}$ ), armadillo

personal con Javier Urcid, 2008; véase también, del mismo autor, Zapotec Hieroglyphic Writing, Washington, D.C., Dumbarton Oaks [Studies in Pre-Columbian Art and Archaeology, 34], 200I, pp. 230-233, fig. 4.I37). 
(fig. 2d) o cánido (fig. 2e), o bien de un saurio (fig. 2f). Los elementos característicos de los mamíferos y saurios están ausentes; por ejemplo, no tiene orejas - que suelen remitir a la primera categoría, aunque no necesariamente- ni el rasgo diagnóstico de la segunda — que es el hocico doblado hacia arriba.

A estas posibles identidades de tal criatura se añade otra según la cual se trata de un ser complejo sin referente en la naturaleza. Hasta este momento, sin profundizar debido a la falta de material comparativo adicional, se puede afirmar que debió pertenecer a los seres que integran la economía de las lluvias. Sin embargo, en esta ocasión no se analizará cada uno de estos animales referentes a este tema.

\section{Identificación iconográfica}

La figurilla porta un huipil de cuatro lienzos, de corte mediano que alcanza a cubrir la cintura y un enredo que cae debajo de la rodilla, al nivel de la pantorrilla. Ambas prendas muestran diseńos que son el soporte de por lo menos cinco complejos iconográficos.

\section{Quinterno y pares de bandas superpuestas}

Sobre el lado derecho del huipil, que tiene algún resto de pintura ocre, se encuentra un pictograma en forma de quinterno cuyos ramales portan una cruz incisa y sus cuatro esquinas, un cuadrado marcado por una incisión circular (fig. 3a). Es parecido al glifo maya T510, ${ }^{5}$ que designa el día Lamat, y significa "estrella" en general y "Venus" en particular (fig. 3 b). Se infiere que corresponde a Venus, en consideración al tema ya anunciado por Tlaloc. La sociedad nahua del altiplano en el Posclásico tardío profesaba a Venus un culto que ilustra la simbología mesoamericana referente a la guerra y al sacrificio. La variante que se desarrolló en el altiplano se ha analizado y resumido en los términos de "guerra-sacrificio-sustento del sol y de la tierra por la sangre". ${ }^{6}$ Venus es lla-

5. Los glifos mayas se reúnen en el catálogo de Eric John Thompson, A Catalogue of Maya Hieroglyphs, Norman, University of Oklahoma Press, 1962.

6. De acuerdo con la terminología empleada por Henry B. Nicholson en su estudio de la religión prehispánica del altiplano mexicano ("Religion in Pre-Hispanic Central Mexico", en Raupert Wauchope (ed.), Middle American Indians, Archaeology of Northern Mesoamerica, Austin, University of Texas Press, vol. X, parte I, pp. 395-446). 
a)

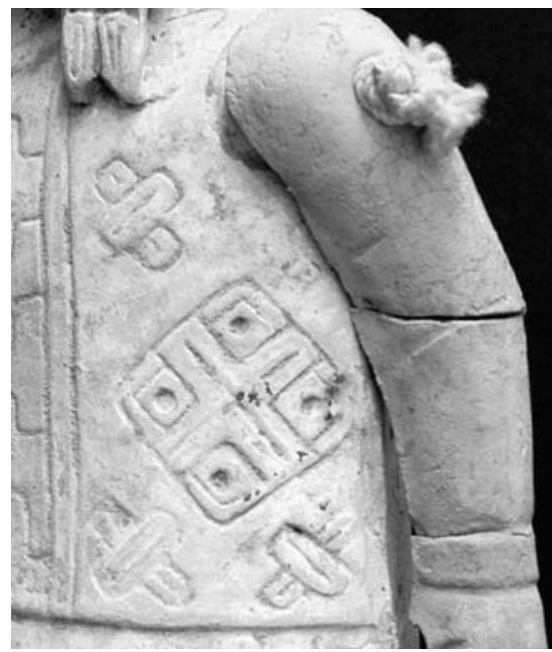

b)

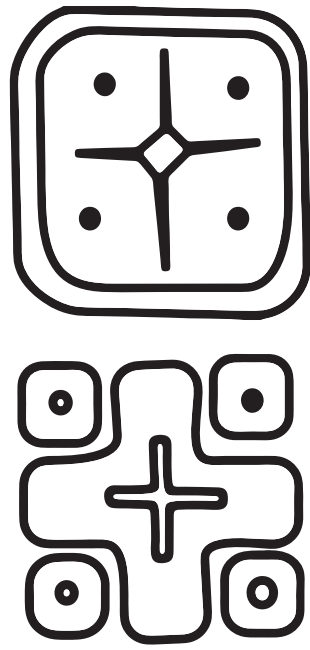

3a) Detalle de PJ282, glifo Lamat flanqueado por bandas superpuestas;

b) glifos Lamat. Dibujos tomados de Davoust, op. cit. (infra n. 36), p. 582, T5 ıо, glifo maya de Venus.

mada Huei Citlalin: estrella grande. ${ }^{7}$ El dios que la encarna es Tlahuizcalpantecuhtli, señor de la Casa de la Aurora ${ }^{8}$ e integrante del complejo MixcoatlCamaxtli, dioses con los que comparte el origen estelar y la naturaleza militar. Sahagún registra que le ofrecían sacrificios humanos. ${ }^{9}$ El régimen sacrificial permite fecundar la tierra como lo consignan las fuentes: la diosa de la tierra, Tlaltecuhtli, "no quería dar fruto, si no era regada con sangre de hombres". ${ }^{\text {Io }}$ La sangre de los guerreros capturados y la del autosacrificio era el chalchiuhatl,

7. Fray Bernardino de Sahagún, Historia general de las cosas de Nueva España, Alfredo López Austin y Josefina García Quintana (est. intr., paleografía, glosario y n.), México, Consejo Nacional para la Cultura y las Artes (Cien de México), 2002, p. 699.

8. Tlahuizcalpantecuhtli es el aspecto resucitado de Quetzalcoatl o Serpiente Emplumada Verde, en la costa del Golfo, donde se incinera en una hoguera para renacer como estrella de la mañana (“Anales de Cuauhtitlán”, P. F. Velázquez [trad.], en Códice Chimalpopoca, México, Universidad Nacional Autónoma de México-Instituto de Investigaciones Históricas, 1975, pp. I-I I7).

9. Fray Bernardino de Sahagún, Florentine Codex: General History of the Things of New Spain, Arthur J.O. Anderson y Charles E. Dibble (trad. y ed.), Salt Lake City, University of Utah, I950-I982, pp. II-I 2.

Io. "Historia de México", en Ángel María Garibay (ed.), Teogonía e historia de los mexicanos, México, Porrúa (Sepan Cuántos...), 2005, pp. 9I-II6. 
“agua preciosa”. I I La sangre roja y el agua azul-verdoso tienen el mismo efecto sobre la tierra. La concurrencia combinada de flujos rojos — sangre- - y azules - agua - caracteriza la imaginería del Posclásico tardío, tanto la maya como la teotihuacana, que le precedió. ${ }^{12}$ La pintura mural de Las Higueras (centronorte de Veracruz), que pertenece al Clásico tardío, pone en escena juegos de pelota donde alternan los líquidos rojos y azules. ${ }^{\mathrm{I} 3}$

Los nahuas del municipio de Ixhuatlán de Madero (norte del estado de Veracruz), cuando dicen que "las aguas de la tierra son su sangre", dan a entender que conocen el sistema de los líquidos preciosos. ${ }^{\text {I4 }}$

En la lengua maya yucateca, ${ }^{15}$ la estrella de Venus se llamó Chac Ek, estrella roja. Las actividades guerreras y las prácticas sacrificiales realizadas bajo la égida de Venus se consignan en la escritura jeroglífica maya en la forma de conjuntos glíficos que incluyen un topónimo, que corresponde a la ciudad atacada, y el

I I. Eduard Seler, Comentarios al Códice Borgia, Mariana Frenk (trad.), México, Fondo de Cultura Económica, I980, pp. 205-206 y 213. En referencia a la dinámica del sacrificio, Soustelle subraya que, para "liberar fuerzas de vida, es necesario verter sangre" (Jacques Soustelle, La pensée cosmologique des anciens mexicains: Représentation du monde et de l'espace, París, Hermann [Actualités Scientifiques et Industrielles, 88r], p. 17). Hoy día, en México y Guatemala, se acostumbra hacer ofrendas que incluyen sangre animal para los seres sobrenaturales telúricos.

I2. John B. Carlson, Venus-regulated Warfare and Ritual Sacrifice in Mesoamerica: Teotihuacan and the Cacaxtla "Star Wars" Connection, Maryland, Center for Archaeoastronomy (Technical Publication, 7), I991, p. I7.

I3. Rubén B. Morante López, comunicación personal, 2008. Véase también La pintura mural de Las Higueras, Veracruz, Xalapa, Universidad Veracruzana, 2005, fragmentos 404I y 4053, pp. 90, 98, I60 y 168.

I4. Alan R. Sandstrom, "Sacred Mountains and Miniature Worlds. Altar Design Among the Nahua of Northern Veracruz, Mexico", en Douglas Sharon (ed.), Mesas and Cosmologies in Mesoamerica, San Diego (San Diego Museum Papers, 42), 2003. Además, el concepto mesoamericano de la antropomorfización del universo ha sido estudiado, por ejemplo, por Alfredo López Austin, Cuerpo humano e ideología: las concepciones de los antiguos nahuas, México, Universidad Nacional Autónoma de México, 1980, y, en la etnografía, entre el grupo nahua veracruzano, por Alan R. Sandstrom, "El nene lloroso y el espíritu nahua del maíz: el cuerpo humano como símbolo clave en la huasteca veracruzana”, en Jesús Ruvalcaba (coord.), Nuevos aportes al conocimiento de la huasteca, México, Centro de Investigaciones y Estudios Superiores en Antropología Social, I998, pp. 59-94, y, entre los grupos otomíes de la Sierra de Puebla e Hidalgo, por Jacques Galinier, "Una mirada detrás del Telón", en Johanna Broda y Jorge Félix Báez (coords.), Cosmovisión, ritual e identidad de los pueblos indígenas de México, México, Biblioteca Mexicana/Consejo Nacional para la Cultura y las Artes/Fondo de Cultura Económica, 200I, pp. 453-484.

I5. "Códice de Dresde", en Codices Selecti, Ferdinand Anders (introd. y resumen), Graz, Akademische Druck und Verlagsanstalt, I975, vol. LIV, ff. 48-50. 
glifo "estrella", identificado como Venus; se transcriben como "Guerra de Estrellas" y "Estrella Concha". David Freidel y otros consideran que la "Guerra de Tlaloc-Venus" era una "institución militar maya". ${ }^{16}$ John Carlson se refiere a un "culto de la guerra" y también al "complejo de la Guerra Tlaloc-Venus". Además, argumenta que se trata de un culto militarista coincidente con los inicios de Teotihuacan en el Formativo tardío, ${ }^{17}$ que dominó la ideología de la ciudad y se expandió en la mayor parte de Mesoamérica. En el contexto de la escritura teotihuacana, tal guerra puede ser referida por el conjunto de "la Gran Estrella con los aros circulares". ${ }^{8}$ Se observa que estamos en presencia de un sistema de pensamiento cuya originalidad se arraiga en la resemantización de los atributos de los dioses del complejo de la lluvia para integrarlos al discurso guerrero. ${ }^{19}$ En el arte escultórico o en la plástica, como por ejemplo en la pintura mural de Cacaxtla, se plasman, si no completos, a manera de pars pro toto, para tomar la función de conjuntos glíficos: la estrella, los aros, el cuchillo de obsidiana o de pedernal, y pictogramas de sangre. ${ }^{20}$ Sobre el mismo costado del huipil de PJ 282, en torno al glifo Venus, se han representado cuatro pares de bandas superpuestas, pictograma que posiblemente corresponde a bandas cruzadas o anudadas, como se puede observar en la vestimenta de otras figurillas de la Mixtequilla.

I6. David Freidel et al., Maya Cosmos: Three Thousand Years on the Shaman's Path, Nueva York, William Morrow, I993, p. 296.

I7. Corresponde al Preclásico tardío, la fase Patlachique (I50 a.C.- Ioo d.C.).

18. Carlson, op. cit., pp. 7 y i i; y John B. Carlson, "Transformations of the Mesoamerican Venus Turtle Carapace War Shield: a Study on Ethnoastronomy. Songs from the Sky, Indigenous Astronomical and Cosmological Traditions of the World", The Journal of the Center for Archaeoastronomy, núms. I2 y I3, 2005, pp. 99-I 22.

19. Inicialmente, se distinguían dos aspectos de la deidad Tlaloc teotihuacana, a los que se llamó Tlaloc A y B. Se asociaba el primero con el cocodrilo y con el simbolismo de la tierra, el agua y la lluvia, y el segundo con el jaguar y el complejo de la guerra y del sacrificio. Esther Pasztory, The Iconography of the Teotihuacan Tlaloc, Washington, D.C., Dumbarton Oaks (Studies in Precolumbian Art and Archaeology, I5), 1974, pp. Io y I8-19; Hasso von Winning, "A Symbol for Dripping Water in the Teotihuacan Culture”, El México Antiguo, vol. 6, núms. 9-I2, I947, pp. 333-34I. Más tarde, se reconoció la "naturaleza doble" de Tlaloc (Marta Foncerrada de Molina, Cacaxtla. La iconografía de los olmeca-xicalanca, México, Universidad Nacional Autónoma de México-Instituto de Investigaciones Estéticas, 1993; James C. Langley, Symbolic Notation of Teotihuacan. Elements of Writing in a Mesoamerican Culture of the Classic Period, Oxford, BAR [International Series, 313], 1986, pp. 75-80).

2o. Janet C. Berlo, "Early Writing in Central Mexico: In Tlilli, In Tlapalli Before A.D. Iooo", en Richard A. Diehl y Janet C. Berlo (eds.), Mesoamerica After the Decline of Teotihuacan A.D. 700-900, Washington, D.C., Dumbarton Oaks, I989, pp. I9-48. 


\section{Signos cruciformes escalonados}

En los lienzos izquierdo y central del huipil se plasmaron cuatro signos cruciformes, uno completo y tres a la mitad, con restos de color ocre, acerca de los cuales Medellín Zenil opinó que eran "cruces griegas que aluden a la divinidad solar" (fig. 4a). ${ }^{2 \mathrm{I}} \mathrm{Su}$ interpretación es congruente con el conocimiento que tenía de los resultados de las investigaciones de Alfonso Caso, quien dio cuenta de la presencia del glifo cruciforme en la banda de frente del glifo del año zapoteco (fig. 4b) y lo catalogó como glifo E. Urcid recuerda que el estudio de Caso se basó en la similitud de dos elementos en el glifo portador del año zapoteco: uno cruciforme, con narigueras de turquesa figuradas en las fuentes ilustradas del altiplano, y un polisémico término náhuatl, xiuitl, que designa, entre otros conceptos, la turquesa y el año solar. Caso modificó posteriormente su interpretación del símbolo de turquesa para asentar que también representa las "cinco regiones del mundo". ${ }^{22}$ En efecto, el "quinterno", como lo describió Caso, forma parte de los signos asociados a Tlaltecuhtli, la diosa telúrica. Urcid concluye que el glifo E designa la tierra en su reparto cuatripartito, tal como lo concibieron los mesoamericanos. ${ }^{23}$

Es notorio que el signo "turquesa" y "sol", identificado en el huipil por Medellín Zenil, carece de una marca circular central: no la tiene este ejemplo, ni otros (por ejemplo la figurilla registrada como PJ287, también procedente de Nopiloa). Por lo tanto, se diferencia del "quinterno" o de la "cruz de cinco elementos" teotihuacanos, y de sus contrapartes mayas, T28I, el glifo "Cruz K'an" (fig. 4c), y T585, el glifo quinterno B'I, "camino" (fig. 4d). ${ }^{24}$ En cambio, en múltiples ejemplos del glifo E, el elemento central está ausente: ${ }^{25}$ una forma particularmente próxima al diseño cruciforme estudiado. En este trabajo se

21. Medellín Zenil, Nopiloa..., op. cit., p. 66.

22. Caso escribió acerca del glifo E: "en mi concepto significa una piedra preciosa, una turquesa que adorna la nariz del dios del ańo" (Alfonso Caso, "Las estelas zapotecas", en Obras. El México antiguo, mixtecas y zapotecas, México, El Colegio Nacional, 2003, vol. 2, p. 22; "Los dioses y signos teotihuacanos", en Teotihuacan: XI Mesa Redonda [1966], México, Sociedad Mexicana de Antropología, 1967, p. 258).

23. Urcid, Zapotec.., op. cit., fig. 4.44. Xiuitl significa "año, hoja, turquesa, calor, cometa, y hierba” (Joseph R. Campbell, A Morphological Dictionary of Classical Nahuatl: A Morpheme Index to the "Vocabulario en lengua mexicana y castellana" of Fray Alonso de Molina, Madison, The Hispanic Seminary of Medieval Studies, 1985, pp. 4I2-4I3).

24. Langley, op. cit., p. 279, n. I7 y 2I4; John Montgomery, Dictionary of Maya Hieroglyphs, Nueva York, Hippocrene Books, 2002, p. 43.

25. Urcid, comunicación personal, 2008. 
interpreta este último como la expresión formulada en barro, pero que muestra un diseño textil de un cosmograma conforme al modelo de estructuración del cosmos dividido en cuatro. El cosmos mesoamericano - en este caso dotado, sin embargo, de las características de un quinterno, con cuatro regiones a las que se suma la quinta dirección correspondiente a la posición del centro, todas asociadas a dioses, colores, árboles y pájaros — ha sido plasmado en los códices. ${ }^{26}$ El principio de cuatro direcciones se aplica a cualquiera de los tres niveles que conforman el universo. Un ejemplo de ello es la cueva situada debajo de la Pirámide del Sol, en Teotihuacan. Tiene una forma cuatrilobulada, acerca de la cual Doris Heyden escribe que "apunta a las cuatro direcciones del universo" ${ }^{27}$

Cartuchos cuatrilobulados o trilobulados provistos de vegetación existen en la iconografía olmeca; por ejemplo, en Chalcatzingo, Relieves I y IX, y en La Venta, Altar 4. Se refieren a cuevas, ojos de agua u oquedades, que son entradas a las montañas y al más allá. ${ }^{28}$

Cada signo o figura cruciforme presenta un contorno escalonado. Trazos ondeados paralelos son el pictograma náhuatl de atl, "agua", aplicado en textil. ${ }^{29}$ Adornan y dan su nombre al huipil y a la falda de la diosa del agua, llamados atlacuilolihuipile y atlacuilolicueitl ${ }^{30}$ en el Posclásico tardío (fig. 5a). En la iconografía teotihuacana, maya (figs. 5b y 5c) y zapoteca, contornos en meandro designan extensiones de agua. Con base en el sistema de representación mesoamericano, se han identificado como bandas de agua los diseños de meandros paralelos en las faldas de las figurillas sonrientes de Los Cerros y Nopiloa. ${ }^{3 \mathrm{I}}$

26. Códice Fejérváry-Mayer, C. A. Burland (introd.), Graz, Akademische Druck und Verlagsanstalt/City of Liverpool Museums, I97I, p. I, ms. I20I4; Codex Tro-Cortesianus (Codex Madrid), Ferdinand Anders (introd. y resumen), Graz, Akademische Druck und Verlagsanstalt, 1967, pp. 75-76. Además, hay un pictograma quinterno en la iconografía olmeca (David Peter Joralemon, Un estudio en iconografía olmeca, Xalapa, Universidad Veracruzana [Textos Universitarios], I990, motivo 177).

27. Doris Heyden, "Caves, Gods and Myths: World View and Planning in Teotihuacan", en Elizabeth P. Benson (ed.), Mesoamerican Sites and World Views, Washington, D.C., Dumbarton Oaks, I98I. 28. Linda Schele y Mary Ellen Miller, The Blood of Kings. Dynasty and Ritual in Maya Art, Nueva York, Fort Worth y George Braziller/Kimbell Art Museum, 1986, p. 257; John B. Carlson, The Margarita Structure Panels and the Maya Cosmogonic Couplet of Ancestral Emergence, Filadelfia, University of Pennsylvania Museum-Early Copán Acropolis Program, 1997, p. 3.

29. Marc Thouvenot, Chalchihuitl. Le jade chez les aztèques, París, Institut d'Ethnologie-Musée de l'Homme, 1982, p. Ioo.

30. Primeros memoriales, Thelma D. Sullivan (paleografía del texto náhuatl y trad. al inglés), University of Oklahoma Press (The Civilization of the American Indian Series), I997, p. I04, f. 263v.

3I. Chantal Huckert, "Representaciones textiles del México precolombino: variaciones en torno al motivo de Xicalcoliuhqui”, en Victoria Solanilla Demestre (ed.), Actas, III Jornadas Interna- 
I 4

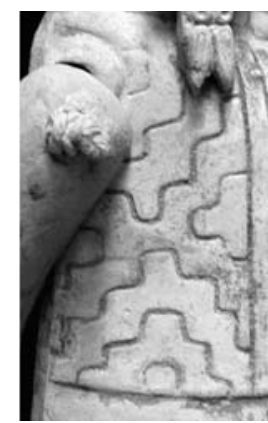

a)
CHANTAL HUCKERT
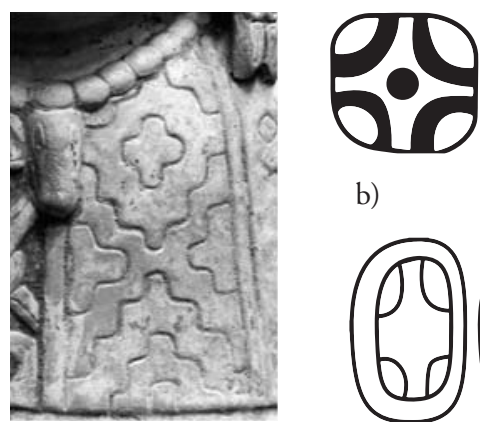

b)
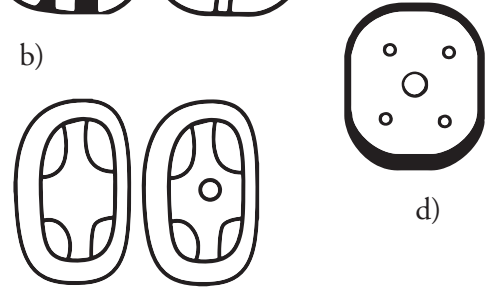

d)

4a) Detalle de PJ282, cosmogramas cruciformes, uno completo y tres a la mitad; b) quinterno en la epigrafía y en el tocado del glifo portador del año zapoteco. Dibujos tomados de Caso, "Las estelas zapotecas", op. cit. (supra n. 22), p. 95, fig. 8; c) el glifo maya T28 I o Cruz K'an. Dibujos tomados de Davoust, op. cit. (infra n. 36), p. 575; d) El glifo quinterno maya T585. Dibujo tomado de Montgomery, op. cit. (supra n. 24), p. 43. Reproducción autorizada por el Instituto Nacional de Antropología e Historia. Conaculta-INAH-Méx.

Nudo o amarre, bandas cruzadas y pares de volutas

En el centro del huipil se observa el motivo de "crótalos serpentinos [y] Nahui Ollin [que] representa los cuatro movimientos del sol" de acuerdo con Medellín Zenil (fig. 6a). El diseño se encuentra plasmado sobre un fondo rojo, y en la profundidad de sus relieves se ha conservado el pigmento de ese color. En el centro se halla el nudo o amarre de un atado o envoltorio. Éste corresponde a lo que Medellín Zenil llamó "crótalos". La atadura o el nudo de un atado figurado por "curvas enclavijadas" o "entrelaces" han sido identificados en placas moldeadas teotihuacanas por von Winning (fig. 6b). ${ }^{32}$ Los ejemplos que compiló este autor representan atados de maderos. Un nudo parecido se encuentra en la epigrafía maya, en el conjunto glífico que describe el "paquete o envoltorio del cargo real", y significa la entronización

cionales sobre Textiles Precolombinos, Barcelona, Departament d'Art de la Universitat Autónoma de Barcelona-Grup d'Estudis Precolombins, 2005, pp. II I-I28.

32. Respectivamente, Hasso von Winning, "The Old Fire God and His Symbolism at Teotihuacan", Indiana, núm. 4, 1977, pp. 7-32, y La iconografía de Teotihuacan. Los dioses y los signos, México, Universidad Nacional Autónoma de México-Instituto de Investigaciones Estéticas (Estudios y Fuentes del Arte en México), I987, t. II, p. 20. 

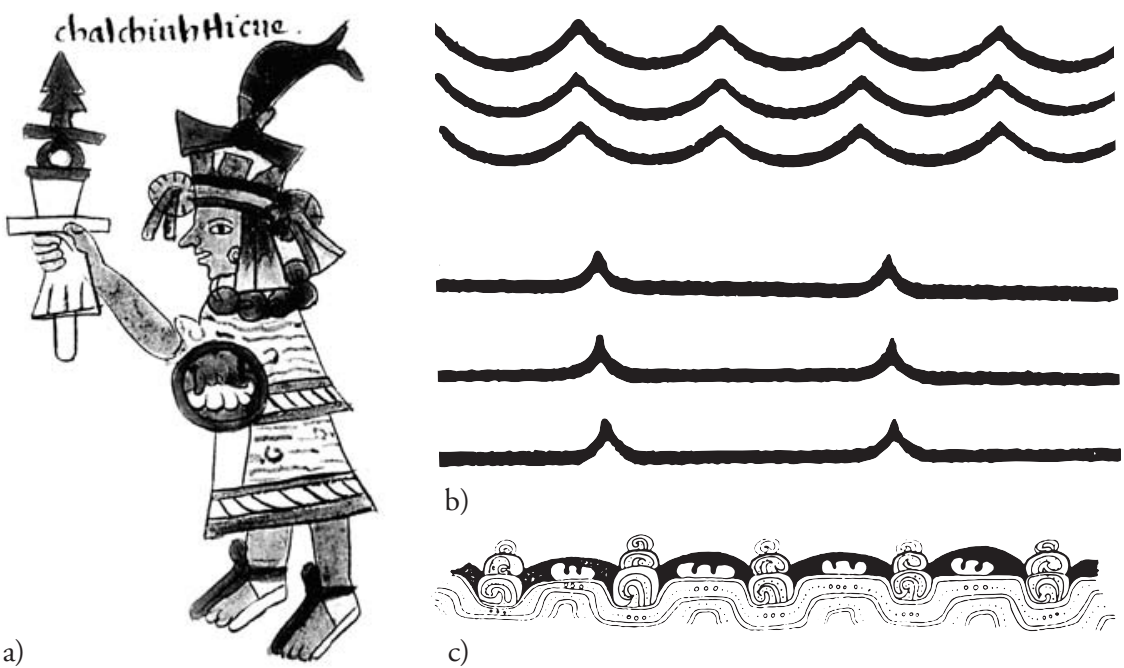

b)

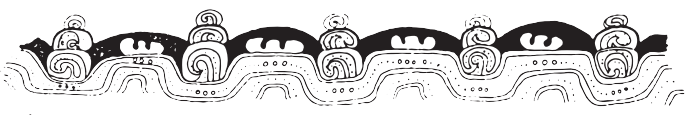

c)

5a) Diseño atlacuiloli en la falda de Chalchiuhtlicue. Imagen tomada de Primeros Memoriales, edición facsimilar, Norman, University of Oklahoma Press (The Civilization of the American Indian Series), I993, fol. 263v.; b) signos notacionales en Teotihuacan, arriba "agua"; abajo, "extensión de agua, o agua". Dibujo tomado de Langley, op. cit. (supra n. I9), p. 273; c) vasija maya (Petén) con banda de agua. Dibujo tomado de Nicholas M. Hellmuth, The Surface of the Underwaterworld: Iconography of the Gods of the Early Classic Maya Art in Peten, Guatemala, Miami, Foundation for Latin American Anthropological Research, I987,

t. II, fig. 39 .

del soberano (fig. 6c). ${ }^{33}$ El envoltorio, o atado, tal como el tlaquimilolli de los mexica, o el Pisom Q'aq'al, de los mayas quichés, ${ }^{34}$ era el receptáculo de los objetos que representan a una deidad, la cual es consustancial a ellos. Los miembros del grupo étnico que le rinden culto lo reciben y tratan como el símbolo de su legitimidad y autoridad.

33. John Montgomery señala que el nudo de amarre no está numerado en el catálogo de Thompson. Montgomery, op. cit., p. II7.

34. Allen J. Christenson, "Bailando en las huellas de los antepasados", en Virginia Fields y Doris Reents-Budet (eds.), Los mayas, señores de la creación. Los orígenes de la realeza sagrada, Consejo Nacional para la Cultura y las Artes-Instituto Nacional de Antropología e Historia/Nerea, 2006; Robert M. Carmack y James L. Mondloch (eds.), El título de Totonacapan, México, Universidad Nacional Autónoma de México, 1983, pp. I75 y I8I-I82. 
I 6

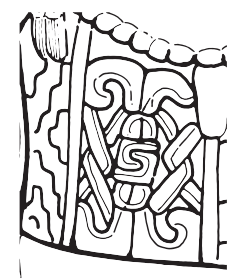

a)

CHANTAL HUCKERT

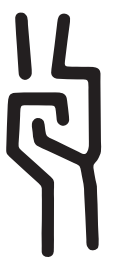

b)

(1)

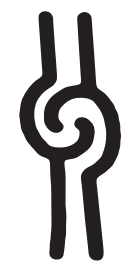

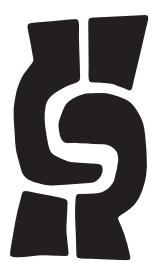

6a) Detalle de PJ282, envoltorio o atado. Dibujo de Juan Pérez Morales; b) "la atadura expresada por entrelaces" del envoltorio o atado. Dibujos tomados de von Winning, La iconografía..., op. cit. (supra n. 32), p. 20, figs. 2 I c, f y j; c) nudo del amarre en el "paquete o envoltorio del cargo real" maya. Dibujo tomado de Montgomery, op. cit. (supra n. 24), p. II7.

A los lados del atado se expanden las bandas o cordeles cruzados a los que Medellín Zenil consideró un posible "Nahui Ollin". Esta identificación se basa en el trabajo de documentación que el mismo autor llevó a cabo respecto a los tocados de las "figurillas sonrientes". Encontró un motivo compuesto de un par de cordeles cruzados que dejan libre un espacio entre ambos y decidió denominarlo "motivo geométrico", distinguiendo dos formas: una en $\mathrm{U}$, a la que asoció con Nahui Ollin, y otra en V, que a su parecer posee "semejanza" con el glifo del mes maya llamado Pop, "estera". ${ }^{35}$ En consecuencia, cada una de las variantes pertenece a un espacio simbólico distinto. El diseño en la prenda de la figurilla PJ282 se constituye de dos elementos cruzados sin espacio intermedio, por lo cual es posible que se diferencie sustancialmente del "motivo geométrico". Por el momento, debido a que no aprecio diferencia evidente con el signo maya "estera", T55 I, particularmente tal como se ha interpretado en el ejemplar enseñado en la figura 8c, me inclino a considerarlo el mismo. ${ }^{36}$

Pares de follaje o de volutas adornan el registro superior e inferior del envoltorio. Conjuntos de follaje o volutas en pares o múltiples son formas

35. Medellín Zenil, Nopiloa..., op. cit., pp. IOI-IO2. Para los nahuas del Posclásico tardío, el mundo en que vivían, Nahui Ollin, 4 Movimiento, fue engendrado por el movimiento ("Leyenda de los soles", P. F. Velázquez [trad.], en Códice Chimalpopoca, México, Universidad Nacional Autónoma de México-Instituto de Investigaciones Históricas, 1975, p. I22).

36. Urcid piensa reconocer en este diseño al glifo A zapoteco que figura un nudo (comunicación personal, 2008). El signo maya "estera" se designa T55 (Michel Davoust, L'écriture maya et son déchiffrement, París, Conseil National de la Recherche Scientifique, I995, p. 62). 
convencionales de representar sangre, 37 nubes, rocío o humedad en general (como se observa en la iconografía de los dioses del agua), así como fuego y humo, ${ }^{38}$ y también el aliento. ${ }^{39}$

Este complejo de elementos integra la imaginería de la comunicación con los ancestros y los dioses: así lo expresa el devoto de Tezcatlipoca: "lo que decimos, lo que pensamos, nuestros pensamientos, nuestros corazones: es como si humo, niebla se alzacen frente a ti". ${ }^{40}$

La dinámica de las prácticas rituales sustituye sustancias y fenónemos — por ejemplo, con la sangre del autosacrificio se tiñe papel que se quema y se convierte en humo, ${ }^{4 \mathrm{I}}$ con la finalidad de que éste ascienda al plano celestial para convertirse en nubes y en lluvia - y los activa para que participen del calor vital y de la esencia numinosa: en el día nahuiecatl los mercaderes ofrendan víveres e incienso "que colocan en el sol" (in ipan in tonalli); de este tipo de práctica "se decía que los mercaderes calentaban las cosas" (ca tlatonaltia... in puchteca). ${ }^{42} \mathrm{La}$ Tercera relación describe cómo los ulmeca xicallanca, xochteca y quiyahuizteca infunden tonalli al agua divina: "en el año [3] calli, le dieron tonalli a su dios, el agua [...] oraban; el humo asciende sobre Cerro Chalchiuhmomoztli, en Tamoanchan". ${ }^{43}$ Igualmente, en Omeyocan, los dioses

37. Schele y Miller, op. cit., pp. 48 y I90, fig. 3 Ic, lám. 65, entre otros.

38. Figuran un conjunto de volutas los signos mayas K'ak', TI22, que significa "fuego" y es la imagen del "humo o lenguas de fuego", y B'utz', Tro35a, que significa "humo" (Montgomery, op. cit., pp. 46 y I 43 ).

39. Karl Andreas Taube, "The Breath of Life. The Symbolism of Wind in Mesoamerica and the American Southwest”, en Virginia M. Fields y Victor Zamudio-Taylor (coords.), The Road to Aztlan. Art from a Mythic Homeland, Los Ángeles, Los Angeles County Museum of Art, 200I, pp. IO2-I23.

40. Sahagún, Florentine Codex..., op. cit., L. 6, p. 25.

4I. El humo del papel que, salpicado de la sangre del autosacrificio, se solía quemar, tenía la finalidad de establecer la comunicación con los antepasados. Los señores mayas conducían desde la época del Preclásico tardío rituales de "autosangradura", concepto designado por el difrasismo maya "(hacer) penitencia-noche", ch'ab-ak'baal (Jean Michel Hoppan y Emilie Jacquemot, "Variabilidad de un difrasismo maya. Emparejamientos con Ch'ab”, en Figuras mayas de la diversidad, Mérida, Centro Peninsular en Humanidades y Ciencias Sociales, 2007, en prensa).

42. Sahagún, Florentine Codex..., op. cit., L. 4-5, pp. 47-48. Duverger señala que "tonalli es por esencia una emanación solar". El término "designa expresamente el calor del sol" y además "no solamente ambos tonalli y tonatiuh 'sol' están formados sobre la misma raíz, sino que gozan de un estrecho parentesco" (Christian Duverger, La flor letal. Economía del sacrificio azteca, México, Fondo de Cultura Económica, I993, p. 8I).

43. Chimalpain Cuauhtlehuanitzin, Domingo Francisco de San Antón Muñón, Memorial breve acerca de la fundación de la ciudad de Culhuacan, Víctor M. Castillo F. (est., paleografía, 
demiurgos, por medio de la acción combinada del soplo y del fuego que producen al rotar el bastón de fuego en el pecho, infunden al embrión su tonalli, la "fuerza animada" o calor y destino.

La sangre sacrificial contiene la fuerza vital divina; se obtiene y se ocupa ritualmente con la finalidad de apropiársela. En esta lógica,

se extraía la fuerza vital [el tonalli] en la sangre para ofrendarla a las deidades y aumentar sus poderes vitales [... a la vez que] la misma presente en la vestimenta y distribuida por el cuerpo era un recurso valioso que el victorioso le tomaba al conquistado para beneficio propio, de su familia, del estado y los dioses. ${ }^{44}$

Los glifos de sangre en la escritura jeroglífica maya ( $\mathrm{T}_{32}-\mathrm{T}_{33}, \mathrm{~T}_{35}-\mathrm{T}_{3} 8, \mathrm{~T}_{40}-$ T4I) se leen k'uh/k'ul, "divino, sagrado". ${ }^{45}$ Atestiguan un pensamiento que asocia la sangre con la energía vital que circulaba por la de los linajes nobles mayas, como lo revela el título real K'ul Ajaw, señor sagrado. ${ }^{46}$ El sistema de reproducción humana que sustenta la filiación circular se observa igualmente entre la nobleza maya como nahua. El señor nahua, recientemente convertido en padre, recibe a su heredero, enviado por los dioses creadores como "un pendiente precioso, una pluma preciosa, su imagen, su sangre, su color, su pelo, su uña"; y el texto remarca con énfasis: "es su sangre". ${ }^{47}$ Hay una relación estrecha entre el concepto de k’uh/kuul maya y el tonalli de los nahuas del Posclásico tardío.

El término ch'ulel, en uso en varias lenguas mayas contemporáneas y construido sobre la raíz chol $c h^{\prime} u$, sería el resultado de un proceso de cambio foné-

trad., n. e índice analítico), México, Universidad Nacional Autónoma de México-Instituto de Investigaciones Históricas (Serie de Cultura Náhuatl, Fuentes, 9), I99I, pp. I04-I05.

44. Jill Leslie Furst McKeever, The Natural History of the Soul in Ancient Mexico, Nueva York, Yale University Press, I995, pp. 65-70, I35 y I37. Duverger llama "ofrenda de energía" al sacrificio de los cautivos y las actividades que le preceden en el contexto del juego de pelota (op. cit., pp. I35-I36 y ss.).

45. David Stuart, "A Note on the 'Hand-scattering' Glyph", Phoneticism in Mayan Hieroglyphic Writing, Albany, State University of New York, núm. 9, 1984, pp. 307-310; John B. Carlson, The Divine King: The Maya God C as the Personification of K'u-, Divinity, Ancestral Spirit and the Soul Residing in the Blood, texto distribuido al mismo tiempo que se realizaba su presentación en el XLVI Congreso de Americanistas, Ámsterdam, 4-8 de julio de I988.

46. Davoust, op. cit., p. I23; Fields y Reents-Budet (eds.), op. cit., p. I37.

47. Sahagún, Florentine Codex..., op. cit., L. 6, pp. I87 y 189. Furst observa que el pelo y las uñas "son depositarios, cargan y transmiten la fuerza vital" (op. cit., p. I26). 
tico. Relevante es el hecho de que el concepto ha permanecido en la cosmovisión actual de sus hablantes. Para los mayas tzotziles de Zinacantán (Chiapas), "todo lo que es importante y valioso" tiene un "alma" ch'ulel que lo habita. Precisa Evon Vogt que esta "alma innata" se localiza no sólo "en el corazón de cada persona [sino que] también se halla en el torrente sanguíneo”. ${ }^{48}$

Los nahuas del municipio de Ixhuatlán de Madero, Veracruz, le llaman chicahualistli a "la energía de la vida transportada por la sangre". ${ }^{49}$ Cronistas y etnógrafos han referido la concepción que los indígenas han tenido y tienen de distintas sustancias inmateriales, llaménseles vitales o anímicas, que habitan el ser humano, lo abandonan en diversas circunstancias y pueden ser eternos o perecederos.

En conclusión, las volutas que se expanden abajo y arriba del nudo o amarre parecen encarnar la energía vital o calor que emana del envoltorio. En cuanto a la función lingüística de éste, merece la pena destacar que, junto con el cacaxtli, ${ }^{50}$ forma parte de difrasismos que designan el oficio de gobernar, el cargo y el ejercicio de la soberanía; por ejemplo: "el gran envoltorio, el gran bastidor para transportar" (in vei qujmjlli, in vei cacaxtli), y "asumirá el envoltorio, asumirá el bastidor para transportar" (tehoatl tiqujnqujmilpatlaz, tiqujncacaxpatlaz). Se le dirige al noble recién nacido la advertencia "Asumirá la carga de la ciudad. Se cansará, sentirá el peso; será el del envoltorio, del bastidor para transportar" (tehoatl ticmamaz in atl, in tepetl, tehoatl ticiaviz, tehoatl teticiviz, tiqujmjle, ticacaxe tiez). Equivale a "la estera de caña, el asien-

48. Evon Vogt, Ofrenda para los dioses, México, Fondo de Cultura Económica, I993, pp. 37-38. Los tzotziles de Chenalhó (Guiteras Holmes, Los peligros del alma. Visión del mundo de un tzotzil, México, Fondo de Cultura Económica, 1996, p. 229), tanto como los tzeltales de Pinola (Esther Hermitte, Poder sobrenatural y control social en un pueblo maya contemporáneo, México, Instituto Indigenista Interamericano-Departamento de Antropología [Ediciones Especiales, 57], I970, p. 77), ubican el ch'ulel en "el cuerpo humano entero". Los cancuqueńos (Cancuc, comunidad tzeltal) lo localizan en el "interior del corazón”, pero esta denominación agrupa varias cualidades o "conjunto de almas" (Pedro Pitarch Ramón, Ch’ulel: una etnografía de las almas tzeltales, México, Fondo de Cultura Económica [Sección de Obras de Antropología], 2006, p. 32). Cada uno de los autores se extiende sobre los significados y los usos del término en la comunidad donde desempeña su investigación. Hermitte (op. cit., pp. 77-100) es una de las primeras, entre los investigadores, que dieron cuenta de la importancia del ch'ulel.

49. Sandstrom, "Sacred Mountains...", op. cit.

50. Cacaxtli, "escallerillas para llevar algo a cuestas" (Alonso de Molina, Vocabulario en lengua castellana y mexicana y mexicana y castellana, México, Porrúa [Biblioteca Porrúa, 44], I970, p. Io). 
to de caña”, que designa la soberanía. ${ }^{51}$ Coincidentemente, un envoltorio de forma similar al PJ282, y por lo tanto de significado semejante, se encuentra pintado en un vaso maya procedente de Dzibilchaltún (Yucatán; fig. 7). Éste destaca por el entrelazamiento central del color rojo y el blanco. En lugar de las bandas laterales enlazadas, tiene segmentos blancos que identifico como tela, y que se integran al nudo del amarre y se colocan a los lados. Pares de follaje o volutas se yerguen arriba y abajo del envoltorio. La imagen se plasma sobre un fondo compuesto por cuatro zonas rectangulares, dos de color rojo-anaranjado y dos de negro. Sobre el lado izquierdo se encuentra el signo "estera" o "petate". 52

\section{Bandas entrelazadas y contorno de lóbulo}

En la falda, del lado derecho, se observan dos extremidades de bandas entrelazadas delineadas en color sepia (fig. 8e). Debido al desgaste, el entrelazamiento completo no es visible. Sin embargo, es probable que se trate de la representación de una estera (figs. 8 a y 8b). Ésta pertenece tanto a la emblemática de la soberanía maya (fig. 8c) como a la nahua. Anteriormente se hizo referencia al difrasismo náhuatl construido sobre la estera y el asiento de caña. ${ }^{53}$ Se observa la marca color sepia del lóbulo de un cartucho, de tal manera que podría formularse esta hipótesis: se trata de la representación de una estera integrada a un cartucho de forma ovaloide o de varios lóbulos. El cartucho cuatrilobulado se encuentra en la vestimenta maya combinado con un amarre formado por cuatro hebras entrelazadas - las cuales revelan una hechura basada en dos vueltas, en un caso, y, en otro, en tres- e insertado en su interior (fig. 8d), y sus diversas apariencias son variantes de las representaciones posibles de la estera.

Hay por lo menos otro ejemplar del signo de estera formado por cuatro hebras entrelazadas en la iconografía de las figurillas sonrientes procedentes de Nopiloa, localizado en el panel frontal del tocado.

51. Sahagún, Florentine Codex..., op. cit., L. 6, pp. 22 y I84. En su versión castellana, "la carga del regimento".

52. Arqueología Mexicana. Sala Maya (edición especial, I5), 2003, jarro procedente de Dzibilchaltún (Yucatán), p. 26.

53. Primeros memoriales, op. cit., pp. 23I, f. 62r. Se expresa de manera rigurosamente idéntica el poder político maya, pop ts'am, "la estera, el asiento" (Hoppan, comunicación personal, 2008). 
7. Vaso procedente de Dzibilchaltún con la representación de un envoltorio. Imagen tomada de Arqueología Mexicana, op. cit. (supra n. 52), p. 26. Reproducción autorizada por el Instituto Nacional de Antropología e Historia. Conaculta-INAH-Méx.

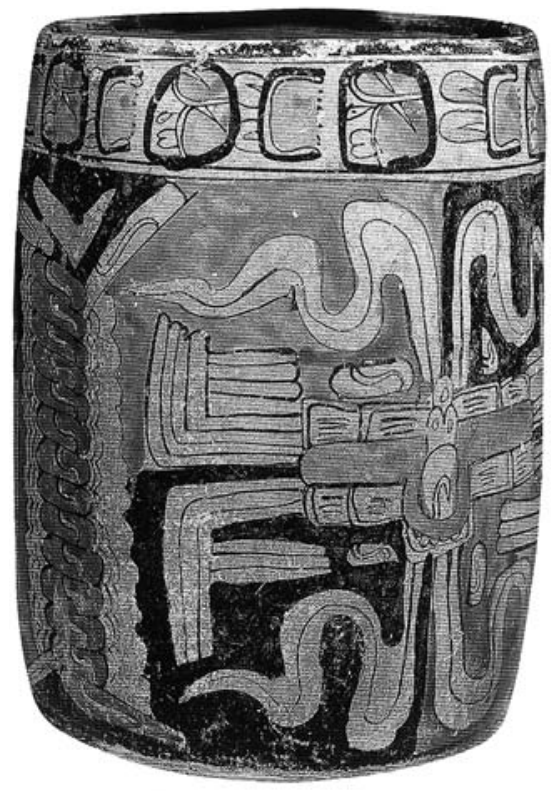

Retícula de cuadrados con disco interior

Sobre el lado derecho de la falda se extiende una retícula vertical de cuadrados con un disco interior de color sepia. Con base en la información registrada por Sahagún, he identificado un diseño con estas características en la vestimenta de la diosa nahua del maíz, Chicomecoatl, como una de las figuras textiles o pictogramas del maíz. ${ }^{54}$ La ceremonia principal dedicada a Chicomecoatl corresponde a la veintena de Huey Toçoztli. Entonces, vestía la falda con el diseño cacamoliuhqui, yn icue cacamoliuhquj ("su falda era una sobrecama"). ${ }^{55} \mathrm{La}$ imagen de la diosa que acompaña el texto (fig. 9a) presenta la vestimenta con el diseño que le da su denominación. Se trata de una retícula vertical compuesta de cuadrados dotados de un disco interior. Fundo el argumento también en el diseño convencional de las mazorcas,

54. Chantal Huckert, "A Case of Continuity: Native Designs of the Otomi Village of San Juan Ixtenco, Tlaxcala", RES: Anthropology and Aesthetics, núm. 42, 2002, pp. 204-225.

55. Sahagún, Florentine Codex... op. cit., L. 2, p. 65. 


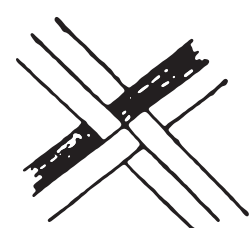

a)

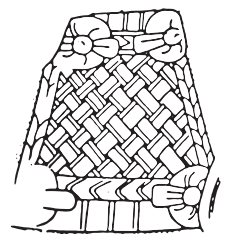

b)

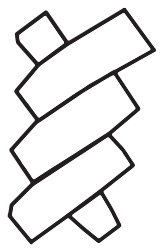

c)

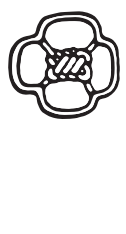

d)

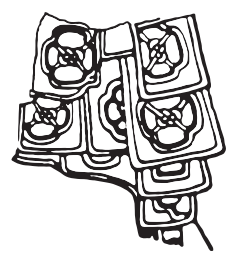

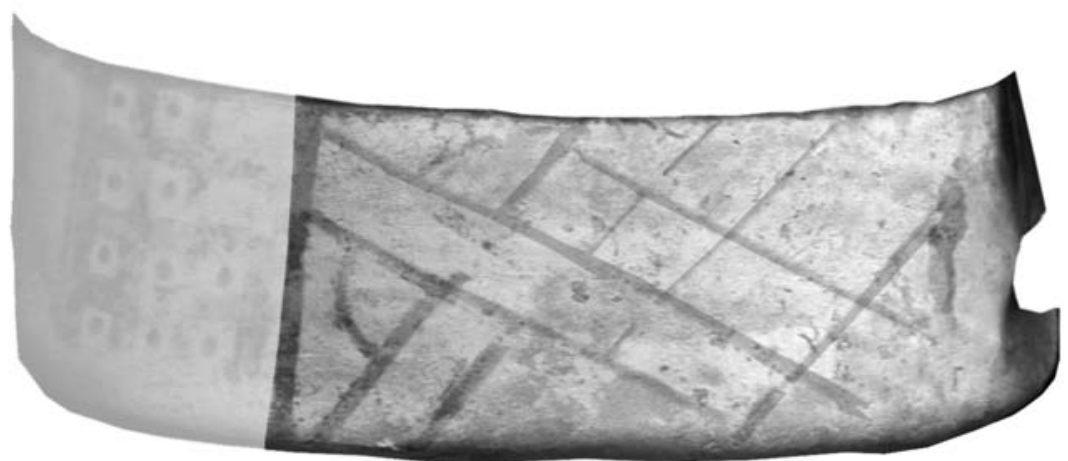

e)

8. Variantes del signo "estera”; a) cuatro hebras entrelazadas. Dibujo de la autora; b) estandarte con el diseño de estera, figurado como hebras que se entrelazan, Dintel 43, Yaxchilán. Dibujo tomado de Ian Graham, Corpus of Maya Hieroglyphic Inscriptions, New Haven/Cambridge, Harvard University-Peabody Museum of Archaeology and Ethnology, 1979, vol. 3, dibujo 95; c) el signo maya T55 I, que se lee pop y designa la "estera". Dibujo tomado de Davoust, op. cit. (supra n. 36), lám. 58; d) respectivamente dinteles 24 y 25 de Yaxchilán, diseño de amarre formado por cuatro hebras entrelazadas que se encuentran integradas a un cartucho cuatrilobulado: en el Dintel 25 los entrelaces son múltiples, y en el 24 son dos. Dibujos tomados de Graham, ibidem, pp. 55 y 53; e) detalle de PJ282, bandas entrelazadas y una forma de lóbulo.

formado por una retícula de cuadrados o de rombos con disco en cada uno, en la iconografía del Posclásico tardío del altiplano. En Chichén Itzás ${ }^{6}$ y en

56. En este caso, podría tratarse de un personificador del dios. Ignacio Marquina, Arquitectura prehispánica. Memorias del Instituto Nacional de Antropología e Historia, México, Secretaría de Educación Pública/Instituto Nacional de Antropología e Historia, I990, pp. 867-868, foto 439; Linda Schele y Peter Mathews identifican el diseño como chalchihuites, o piedra de jade (The 
Cacaxtla (Clásico tardío), el dios del maíz lleva, respectivamente, el atuendo y el tocado de mazorca, trazados ambos con una retícula vertical con discos interiores (figs. $9 \mathrm{~b}$ y $9 \mathrm{c}$ ).

El tema icónico de una palma de piedra, del Clásico tardío, procedente de Veracruz, ${ }^{57}$ consiste en dos mazorcas esculpidas conforme a un patrón de cuadrados con una depresión interna repetido en una retícula vertical (fig. 9d). Este último ejemplo permite afirmar que para las culturas de Veracruz la figura de retícula de cuadrados con discos internos, así como se encuentra pintada en la falda, representa el maíz o la mazorca.

\section{Conclusión}

La imaginería de esta figurilla del Clásico tardío muestra elementos que resultan panmesoamericanos por sus formas y por las ideas que transmiten. Por un lado, el complejo del dios de la lluvia con sus aros se inspira en las convenciones teotihuacanas de representación, lo cual no significa una influencia directa, sino la difusión de un sustrato ideológico-religioso en distintas partes de Mesoamérica. Por otra parte, el uso del glifo "estrella" —en este caso "Venus" - , la estera en su cartucho lobulado y el envoltorio indica un conocimiento de la epigrafía e iconografía mayas, mientras que el empleo del glifo Epsilon señala ciertamente nociones de la epigrafía zapoteca. En el Clásico tardío, por la costa del Golfo transitan las rutas o corredores que unen el altiplano y la región maya de Tabasco y Campeche. La propia geohistoria y la diversidad de recursos de esas áreas dieron lugar a sociedades multiculturales. Forman un territorio de síntesis, como lo prueban la arqueología y la historia del arte. En el Protoclásico, el asentamiento mayor del centro-sur de Veracruz, el Cerro de las Mesas, mantenía relaciones con la costa del Golfo central, las tierras bajas mayas y la capital zapoteca, Monte Albán. ${ }^{58}$

Code of Kings: The Language of Seven Sacred Maya Temples and Tombs, Nueva York, Scribner, I998, p. 252).

57. Palma en custodia del Denver Art Museum (Michael Whittington [ed.], The Sport of Life and Death. The Mesoamerican Ballgame, Charlotte, Mint Museum of Art/Thames and Hudson, 200I, p. 26I, fig. 134).

58. Además de los corredores terrestres, a los que apuntala, Morante señala la "posibilidad de vías fluviales y marítimas", Rubén B. Morante López, "Del altiplano a la costa del Golfo: intercambios culturales y materiales", en María Elena Ruiz Gallut y Arturo Pascual Soto (eds.), 

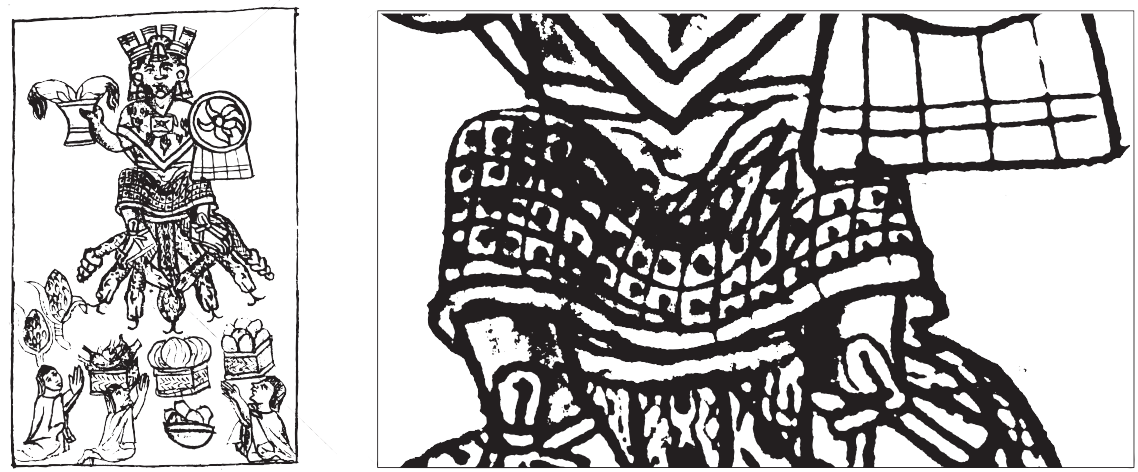

a)

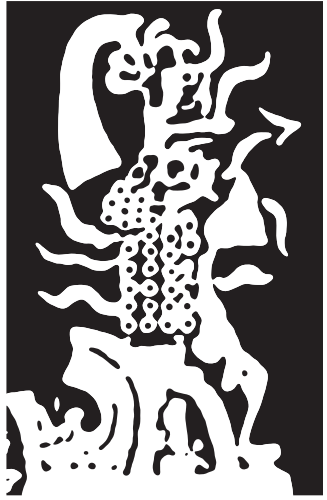

b)

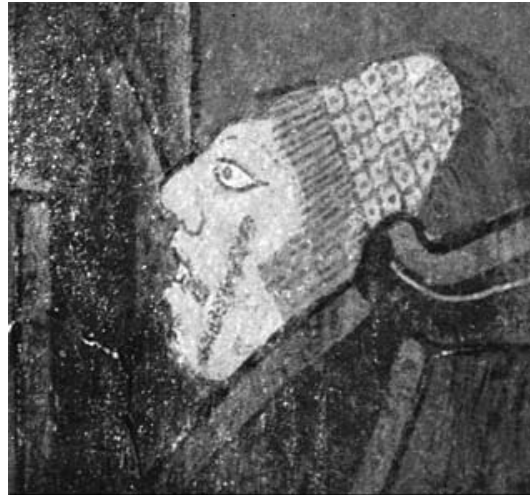

c)

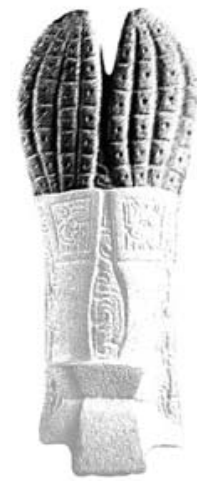

d)

9. Figura de retícula vertical con cuadrados marcados por un disco interior; a) Chicomecoatl, diosa del maíz, viste la falda con el diseño cacamoliuhqui. Dibujo tomado de fray Bernardino de Sahagún, Códice florentino: El manuscrito 2 18-20 de la Colección Palatina de la Biblioteca Medicea Laurenziana, México/Florencia, Archivo General de la Nación/Giunti Barbèra, I979, lib. 2, fol. 29v.; b) el dios del maíz o su personificador humano en el Templo Norte del Juego de Pelota, Chichén Itzá; su vestimenta es una mazorca. Dibujo tomado de Marquina, op. cit. (supra n. 56), foto 439; c) el dios del maíz lleva en tocado una mazorca, Templo Rojo, Palacio de Cacaxtla. Foto: John B. Carlson. Reproducción autorizada por el Instituto Nacional de Antropología e Historia. Conaculta-INAH-Méx.; d) palma que representa dos mazorcas, procedente de Veracruz. Imagen tomada de Whittington, op. cit. (supra n. 57), p. 26 I, fig. I 34 . 
Durante el Clásico temprano, en la iconografía del Cerro de las Mesas perduran rasgos de un pasado olmeca e izapeño, a la vez que se añaden elementos diagnósticos teotihuacanos y mayas. ${ }^{99}$ En cuanto a las referencias etnográficas, se ha buscado poner el acento sobre valores sedimentados en la historia prehispánica.

Dominan la lectura Tlaloc y Venus, bajo cuyo influjo se regula la economía del sacrificio humano, principio fecundador de la tierra. Se propone que la figura cruciforme de color amarillo o crema es un cosmograma referente a un lugar hipoctónico que almacena y produce líquidos preciosos.

El atado provisto de volutas teñidas de rojo vibra con el poder numinoso de la sangre y de todas las sustancias que son sagradas. Las bandas o cordeles cruzados que lo flanquean parecen figurar la estera, pero es posible que se trate del glifo Ollin, o aun de un nudo. El conjunto corresponde a un emblema de realeza y de autoridad militar. Esta interpretación se encuentra respaldada por los difrasismos, donde tal es el significado del envoltorio en el idioma náhuatl. Además, parece que el enredo de la figurilla lleva pintado un signo "estera". El atado constituye con el cosmograma cruciforme una unidad significativa, tal vez en su función de ofrenda, asociada a este espacio acuático particular. Como se trata de prácticas militares y de sacrificio, resulta notorio que el medio de soporte de esta iconografía es un personaje femenino.

No es extraño, sin embargo, que se plasme en la vestimenta de una figura femenina, ya que las diosas en Mesoamérica están ligadas a la fecundidad de la

La costa del Golfo en tiempos teotihuacanos: propuestas y perspectivas. Memoria de la Segunda Mesa Redonda de Teotihuacan, México, Instituto Nacional de Antropología e Historia, 2004, pp. 23-43. La Segunda Mesa Redonda de Teotihuacan se dedicó al tema de la presencia teotihuacana en la costa del Golfo y viceversa: en particular, Barbara L. Stark y Kevin M. Johns tratan las relaciones entre Teotihuacan y la Mixtequilla en su artículo "Veracruz Sur-Central en tiempos teotihuacanos", en Ruiz Gallut y Pascual Soto (eds.), op. cit., pp. 307-327.

59. Flora Clancy subraya que las estelas de los sitios de las tierras bajas mayas del Petén, Guatemala (Sculpture in the Ancient Maya Plaza: The Early Classic Period, Albuquerque, University of New Mexico Press, 1999, pp. 74-77), registran fechas en la cuenta larga maya (Mathew W. Stirling, "Monumental Sculpture of Southern Veracruz and Tabasco", en Raubert Wauchope [ed. gral.] y Gordon R. Willey [ed.], Handbook of Middle American Indians, Archaeology of Southern Mesoamerica, Austin, University of Texas Press, vol. III, núm. 2, I980, pp. 716-738; Michael D. Coe, "Archaeological Synthesis of Southern Veracruz and Tabasco", en ibidem, pp. 679-715). En el mismo sitio, sin embargo, la estela is describe al dios de la lluvia y la tempestad en el estilo teotihuacano (Karl Andreas Taube, The Writing System of Ancient Teotihuacan, Barnardsville, Center for Ancien American Studies [Ancient America, I], 200o, p. 44). En su obra Nopiloa... (op. cit.), Medellín Zenil ya demuestra ciertas semejanzas estilísticas entre Nopiloa y Teotihuacan, y entre el primero y Monte Albán (pp. 35, I 43-I 45, I52, I55, I57 y I64). 
tierra. ${ }^{60}$ En este caso, los alimentos estarían representados por el motivo que identifico como maíz. El papel femenino en el ciclo del maíz queda asentado en el Popol Vuh. Xquic, la mujer joven, un aspecto de la Luna, de acuerdo con Dennis Tedlock, preñada por Hun-Hunahpu y progenitora de los gemelos héroes, activa el inicio del ciclo del maíz en la milpa terrestre. ${ }^{6 \mathrm{I}}$ Eric J. Thompson analiza la asociación de las diosas lunares con el agua y el maíz. ${ }^{62}$ Esther Pasztory observa que la gran diosa de Teotihuacan, en los murales de Tepantitla, se encuentra sentada sobre una construcción de "talud-tablero" que contiene una cueva, y señala que este pedestal representa una montaña. ${ }^{63}$ La diosa madre tierra, joven y fecunda, se asocia a Tlaloc y al sistema que rige la economía de las aguas; es la Madre Montaña. ${ }^{64}$ Los ríos que emanan de su cueva o vientre son de color rojo y azul. Despliegan una vegetación exuberante. El concepto de las montañas dueñas de las aguas y de las semillas encarna en la gran diosa y en las diosas del sustento nahuas: Chalchiuhtlicue, Chicomecoatl y Uixtocihuatl, quienes radican en el Tlalocan, el Cerro de Tlaloc. En consecuencia, se plantea la hipótesis de que la figurilla PJ282 constituye un modelo de gran majestuosidad de las diosas madres telúricas, cuyos interiores orográficos o vientres generan la abundancia. \$s

6o. Doris Heyden, "Las diosas del agua y de la vegetación", Anales de Antropología, Etnología y Lingüistica, vol. XX, núm. 2, I983; Janet C. Berlo, "Icons and Ideologies at Teotihuacan: The Great Goddess Reconsidered", en Art, Ideology and the City of Teotihuacan. A Symposium at Dumbarton Oaks, October $8^{\text {th }}-9^{\text {th }}$, Washington, D.C., Dumbarton Oaks, 1988, p. I49.

61. Dennis Tedlock, Popol Vuh. The Definitive Edition of the Mayan Book of the Dawn of Life and Glories of Gods and Kings, Dennis Tedlock (trad.), Nueva York, Simon \& Shuster, 1985, p. 328.

62. Eric J. Thompson, The Moon Goddess in Middle America with Notes on Related Deities, Washington, D.C., Carnegie Institution of Washington (Publications, 509; Contributions, 29), I939, pp. I30 y I 43 -I 44 .

63. Fase tardía de Xolalpan o fase Metepec -600-750 d. C.—, véase Esther Pasztory, The Murals of Tepantitla, Teotihuacan, Nueva York/Londres, Garland, I976, pp. 54-55 y 165-169.

64. Sahagún, Florentine Codex..., op. cit., L. I I, p. 247; fray Diego Durán, Book of the Gods and Rites and the Ancient Calendar, Fernando Horcasitas y Doris Heyden (trad. al inglés y ed.), Miguel León-Portilla (introd.), Norman, University of Oklahoma Press (Civilization of the American Indian Series), 1971, p. 256. 